\title{
PEMODELAN DAN ANALISIS KESTABILAN SISTEM MEMRISTOR KUBIK ORDE EMPAT
}

\author{
PUTRI HANDAYANI, MAHDHIVAN SYAFWAN, EFENDI \\ Program Studi Matematika, \\ Fakultas Matematika dan Ilmu Pengetahuan Alam, Universitas Andalas, \\ Kampus UNAND Limau Manis Padang, Indonesia, \\ email : putryhandayani95@gmail.com
}

\begin{abstract}
Abstrak. Pada penelitian ini, model sistem memristor kubik orde empat diformulasi dari hukum sirkuit Kirchhoff dan hukum induksi Faraday dengan menggunakan memduktansi yang dikarakterisasi oleh fungsi kuadrat definit positif. Dengan menggunakan kriteria Routh-Hurwitz, ditinjau kestabilan sistem di sekitar titik ekuilibrium. Hasil yang diperoleh menunjukkan bahwa solusi sistem memristor kubik orde empat stabil. Beberapa contoh kasus yang diselesaikan secara numerik telah mengkonfirmasi hasil analisis tersebut.
\end{abstract}

Kata Kunci: Memristor kubik orde empat, kriteria Routh-Hurwitz, hukum sirkuit Kirchhoff, hukum induksi Faraday, Runge-Kutta orde empat

\section{Pendahuluan}

Pada tahun 2008, tim peneliti dari perusahaan Hewlett-Packard di California berhasil mengembangkan komponen elektronik unik yang disebut memristor, yang merupakan singkatan dari memori resistor. Memristor merupakan komponen elektronik dasar keempat setelah resistor, kapasitor, dan induktor. Secara teoritis, eksistensi dari memristor telah dikaji sebelumnya oleh Leon Chua dari University Barkeley, California yang dipublikasikan pada tahun 1971 [2].

Pada dasarnya sebuah memristor adalah sebuah resistor dengan memori. Memristor merupakan sebuah hambatan listrik yang menyimpan informasi seperti halnya dalam ingatan manusia. Dengan adanya memristor, sistem komputer dapat mengingat semua informasi dengan konsumsi daya yang sangat kecil dibanding perangkat daya yang ada saat ini, dan dapat dihidupkan atau dimatikan seperti sebuah saklar lampu [5].

Itoh dan Chua [4] telah membahas analisis persamaan dasar dari beberapa tipe osilator memristor nonlinear yang diperoleh setelah menggantikan diode Chua dengan memristor. Botta [3] kemudian membahas kembali model Itoh dan Chua [4], namun dengan mengganti fungsi memduktansi dengan suatu fungsi kuadrat definit positif, dan parameter yang digunakan adalah parameter yang positif saja. Model memristor Botta ini diperoleh dengan menghapus resistor dari rangkaian listrik yang dimodelkan oleh Chua sebelumnya. Model ini dikenal dengan sistem memristor kubik orde empat. Pembahasan pada penelitian ini mengeksplorasi kembali kajian pada referensi [3]. 
2 Putri Handayani dkk.

\section{Sistem Memristor}

Memristor adalah perangkat listrik pasif dengan dua terminal dimana fluks magnetik $\varphi$ antara terminal merupakan fungsi dari jumlah muatan listrik $q$ yang melewati perangkat ini [5]. Disebut elemen pasif karena tidak dapat dengan sendirinya membangkitkan tegangan atau arus. Simbol dari memristor diperlihatkan oleh Gambar 1.

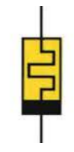

Gambar 1. Simbol Memristor

Setiap memristor dikarakterisasi berdasarkan fungsi memristansi $M$ dan fungsi memduktansi $W$. Memristansi $M$ yaitu besaran perubahan fluks terhadap perubahan muatan dan memduktansi $W$ adalah besaran perubahan muatan terhadap perubahan fluks [4]. Secara matematis hal ini didefinisikan sebagai

$$
\begin{aligned}
M(q) & =\frac{d \varphi(q)}{d q}, \\
W(\varphi) & =\frac{d q(\varphi)}{d \varphi} .
\end{aligned}
$$

\section{Formulasi Model Sistem Memristor Kubik Orde Empat}

Sistem memristor dianalisis secara mendalam oleh Itoh dan Chua [4] dengan sirkuit listrik seperti yang ditunjukkan pada Gambar 2. Dengan mengaplikasikan hukum

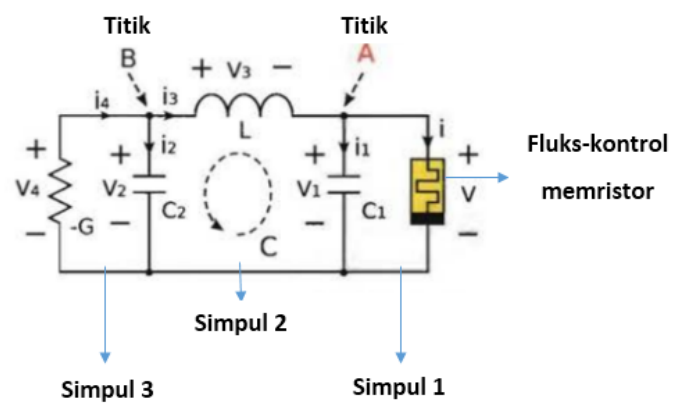

Gambar 2. Sistem Memristor Itoh dan Chua 
sirkuit Kirchoof pada Gambar 2 diperoleh:

$$
\begin{aligned}
I_{1} & =I_{3}-I, \\
V_{3} & =V_{2}-V_{1}, \\
I_{2} & =-I_{3}+I_{4}, \\
V_{2} & =V_{4}, \\
V & =V_{1} .
\end{aligned}
$$

Dengan menerapkan hubungan antara tegangan $V$ dan kuat arus $I$ untuk empat komponen elektronik dasar $(C, L, R, W(\varphi))$, maka sistem (3.1) dapat diubah menjadi sistem persamaan diferensial orde satu, yaitu :

$$
\begin{aligned}
C_{1} \frac{d V_{1}}{d t} & =I_{3}-W(\varphi) V_{1}, \\
L \frac{d I_{3}}{d t} & =V_{2}-V_{1} \\
C_{2} \frac{d V_{2}}{d t} & =-I_{3}+G V_{2}, \\
\frac{d \varphi_{2}}{d t} & =V_{4} \\
\frac{d \varphi}{d t} & =V_{1}
\end{aligned}
$$

Dalam penelitian ini, sistem memristor Itoh dan Chua pada Gambar 2 dilepas komponen resistornya dari sirkuit listrik sehingga diperoleh sirkuit memristor Botta seperti yang ditunjukkan pada Gambar 3 .

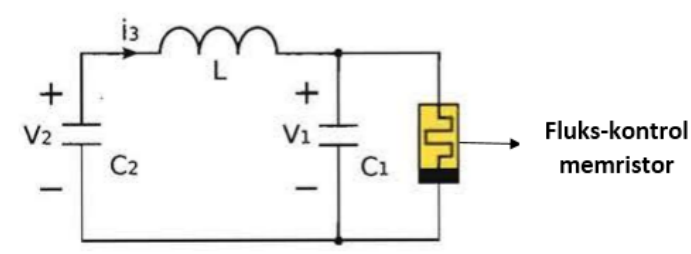

Gambar 3. Sirkuit Memristor Botta

Dengan demikian sistem persamaan (3.2) menjadi

$$
\begin{aligned}
C_{1} \frac{d V_{1}}{d t} & =I_{3}-W(\varphi) V_{1}, \\
L \frac{d I_{3}}{d t} & =V_{2}-V_{1}, \\
C_{2} \frac{d V_{2}}{d t} & =-I_{3} \\
\frac{d \varphi}{d t} & =V_{1}
\end{aligned}
$$


Untuk penyederhanaan perhitungan, sistem persamaan (3.3) ditransformasi menjadi

$$
\begin{aligned}
& \frac{d x}{d t}=\alpha(y-W(w) x), \\
& \frac{d y}{d t}=-\xi(x+z), \\
& \frac{d z}{d t}=\beta y, \\
& \frac{d w}{d t}=x,
\end{aligned}
$$

dimana $x=V_{1}, \alpha=\frac{1}{C_{1}}, y=I_{3}, \beta=\frac{1}{C_{2}}, z=-V_{2}, \xi=\frac{1}{L}, w=\varphi$, sedangkan fungsi kubik $q(w)$ dan $W(w)$ diberikan berturut-turut oleh

$$
\begin{aligned}
q(w) & =w^{3}+a w^{2}+b w+c, \\
W(w) & =3 w^{2}+2 a w+b,
\end{aligned}
$$

dengan $a^{2}-3 b \leq 0$. Karena $C_{1}, C_{2}$, dan $L$ dibatasi bernilai positif, maka $\alpha, \beta$, dan $\xi$ juga bernilai positif.

\section{Kriteria Stabil}

Untuk menganalisis kestabilan titik ekuilibrium, maka perlu diperiksa apakah bagian riil dari semua nilai eigen matriks Jacobiannya bernilai negatif. Salah satu cara yang dapat digunakan adalah kriteria Routh-Hurwitz. Kriteria Routh-Hurwitz merupakan suatu metode yang digunakan untuk menunjukkan kestabilan sistem dengan memperhatikan koefisien dari persamaan karakterisik tanpa menghitung akar-akar secara langsung.

Teorema 4.1. [1] Misalkan $a_{0}, a_{1}, a_{2}, \cdots, a_{n}$ adalah bilangan riil dan tetapkan $a_{k}=0$ jika $k>n$, maka semua akar polinomial

$$
p(z)=a_{0} z^{n}+a_{1} z^{n-1}+\cdots+a_{n-1} z+a_{n}, \text { dengan } a_{0}>0,
$$

mempunyai bagian riil negatif jika dan hanya jika determinan

$$
\Delta_{k}=\left(\begin{array}{ccccc}
a_{1} & a_{3} & a_{5} & \ldots & a_{2 k-1} \\
a_{0} & a_{2} & a_{4} & \ldots & a_{2 k-2} \\
0 & a_{1} & a_{3} & \ldots & a_{2 k-3} \\
0 & a_{0} & a_{2} & \ldots & a_{2 k-4} \\
0 & 0 & a_{1} & \ldots & a_{2 k-5} \\
\vdots & \vdots & \ddots & \vdots \\
0 & 0 & 0 & \ldots & a_{k},
\end{array}\right)
$$

untuk setiap $k=1,2, \cdots, n$ bernilai positif. 


\section{Analisis Kestabilan Sistem Memristor Kubik Orde Empat}

Titik ekuilibrium dari sistem (3.4) adalah

$$
E=\left\{(x, y, z, w) \in \mathbb{R}^{4} \mid x=y=z=0, w \in \mathbb{R}\right\},
$$

dan matriks Jacobiannya adalah

$$
J=\left(\begin{array}{cccc}
-\alpha W(w) & \alpha & 0 & 0 \\
-\xi & 0 & -\xi & 0 \\
0 & \beta & 0 & 0 \\
1 & 0 & 0 & 0
\end{array}\right)
$$

Nilai eigen dari matriks Jacobian tersebut adalah $\lambda_{1}=0$ dan $\lambda_{2,3,4}$ yang merupakan solusi dari persamaan kubik

$$
P(\lambda)=\lambda^{3}+\alpha W(w) \lambda^{2}+(\alpha+\beta) \xi \lambda+\alpha \xi \beta W(w) .
$$

Untuk memeriksa akar-akar dari persamaan kubik (5.1), digunakan kriteria RouthHurwitz, sehingga diperoleh

$$
\begin{aligned}
\Delta_{1} & =\alpha W(w), \\
\Delta_{2} & =\alpha^{2} \xi W(w, \\
\Delta_{3} & =\alpha^{3} \beta \xi^{2} W(w) .
\end{aligned}
$$

Karena $\Delta_{k}, k=1,2,3$, bergantung pada fungsi memduktansi $W(w)$, maka akan dicari nilai-nilai $w$ dari fungsi memduktansi tersebut. Akar-akar dari fungsi memduktansi adalah

$$
\begin{aligned}
& w_{1}=-\frac{1}{3} a+\frac{1}{3} \sqrt{a^{2}-3 b}, \\
& w_{2}=-\frac{1}{3} a-\frac{1}{3} \sqrt{a^{2}-3 b} .
\end{aligned}
$$

Karena di awal sudah dibatasi $a^{2}-3 b \leq 0$, maka akan ditinjau dua kasus, yaitu $a^{2}-3 b<0$ dan $a^{2}-3 b=0$.

(1) Kasus $a^{2}-3 b<0$.

Jika $a^{2}-3 b<0$, maka diperoleh akar-akar $w_{1}$ dan $w_{2}$ yang bernilai kompleks. Dengan demikian fungsi kuadrat $W(w)$ selalu positif untuk semua $w \in \mathbb{R}$. Akibatnya $\Delta_{1}, \Delta_{2}, \Delta_{3}>0$, karena $\alpha, \xi, \beta>0$. Jadi berdasarkan kriteria RouthHurwitz, bagian riil dari semua akar persamaan (5.1) bernilai negatif, sehingga titik ekuilibrium $E$ stabil.

(2) Kasus $a^{2}-3 b=0$.

Jika $a^{2}-3 b=0$, maka diperoleh akar kembar $w_{1}=w_{2}=-\frac{1}{3} a$. Pandang dua subkasus :

Subkasus (2.1). $w \neq-\frac{1}{3} \alpha$

Pada subkasus ini, fungsi kuadrat $W(w)$ selalu positif sehingga $\Delta_{k}>$ $0, k=1,2,3$. Dengan demikian titik $E$ stabil.

Subkasus (2.2). $w=-\frac{1}{3} \alpha$ 
Pada subkasus ini $W(w)=0$, sehingga kriteria Routh-Hurwitz tidak bisa digunakan. Namun dengan mensubstitusikan nilai $W(w)=0$ pada persamaan kubik (5.1), akan diperoleh akar-akar $\lambda_{2}=0$ atau $\lambda_{3,4}=$ $\pm i \sqrt{(\alpha+\beta) \xi}$. Perhatikan bahwa bagian riil dari semua nilai eigen $\lambda_{i}$ bernilai nol, sehingga titik ekuilibrium $E=\left(0,0,0,-\frac{1}{3} a\right)$ stabil.

\section{Kesimpulan}

Berdasarkan hasil formulasi model dan analisis kestabilan, diperoleh bahwa :

1. Model memristor kubik orde 4 diberikan oleh

$$
\begin{aligned}
& \frac{d x}{d t}=\alpha(y-W(w) x), \\
& \frac{d y}{d t}=-\xi(x+z), \\
& \frac{d z}{d t}=\beta y, \\
& \frac{d w}{d t}=x .
\end{aligned}
$$

dengan $x=V_{1}, \alpha=\frac{1}{C_{1}}, y=I_{3}, \beta=\frac{1}{C_{2}}, z=-V_{2}, \xi=\frac{1}{L}, w=\varphi$ dan $W(w)=w^{3}+2 a w+b$.

2. Titik ekuilibrium dari sistem memristor di atas adalah

$$
E=\left\{(x, y, z, w) \in \mathbb{R}^{4} \mid x=y=z=0, w \in \mathbb{R}\right\} .
$$

3. Berdasarkan analisis kestabilan, diperoleh hasil bahwa titik ekuilibrium $E$ akan stabil jika nilai-nilai parameter memenuhi

$$
\left.\left\{(\alpha, \beta, \xi, a, b) \in \mathbb{R}^{5} \mid \alpha, \beta, \xi>0 \text { dan } a^{2}-3 b \leq 0\right)\right\},
$$

\section{Ucapan Terima Kasih}

Penulis mengucapkan terima kasih kepada Bapak Zulakmal, M.Si, Bapak Dr. Effendi dan Ibu Monika Rianti Helmi, M.Si yang telah memberikan masukan dan saran sehingga makalah ini dapat diselesaikan dengan baik.

\section{Daftar Pustaka}

[1] G. J Olsder. 1994. Mathematical System Theory. Delft, Delft University Press.

[2] Chua, Leon O. 1971. Memristor The Missing Circuit Element. IEEE Transactions on Circuit Theory. $18: 507-519$.

[3] Botta, Vanessa. 2013. Stability Analysis of Fourth-Order Cubic Memristor Oscillator. Proceeding Series of the Brazilian Society of Applied and Computational Mathematics. $1: 1-4$.

[4] Itoh, M dan Chua, L.O. 2008. Memristor Oscillators, Internat. J. Bifur. Chaos Appl. Sci. Eng. 18 : 3183-3206.

[5] Arthur, Franciscus. 2009. Konsep Dasar Memristor : Analisis Kurva I-V Titanium Dioxide Memristor. Universitas Indonesia, Jakarta. 